\title{
Exploiting the semiconductor-metal phase transition of VO2 materials: a novel direction towards tuneable devices and systems for RF-microwave applications
}

\author{
Crunteanu Aurelian'1, Givernaud Julien¹, Blondy Pierre1, \\ Orlianges Jean-Christophe ${ }^{2}$, Champeaux Corinne ${ }^{2}$ \\ and Catherinot Alain ${ }^{2}$ \\ ${ }^{1}$ XLIM, CNRS/ Université de Limoges \\ 2SPCTS, CNRS/ Université de Limoges
}

France

\section{Introduction}

Increasing demands for reconfigurable microwave and millimeter-wave circuits are driven for their high-potential integration in advanced communication systems for civil, defense or space applications (multi-standard frequency communication systems, reconfigurable / switchable antennas, etc.). A wide range of tunable and switchable technologies have been developed over the past years to address the problems related to the overlapping of the frequency bands allocated to an ever-increasing number of communication applications (cellular, wireless, radar etc.). Usually, the reconfiguration of such complex systems is realized by using active electronics components (semiconductor-based diodes or transistors) (Pozar, 2005) or, at an incipient stage, RF MEMS (Micro-electro-mechanical systems)-based solutions (Rebeiz, 2003). However, the performances of these systems are sometimes limited by the power consumption and non-linear behaviour of the semiconductor components or by the yet-to-be-proved reliability of the MEMS devices (switches or variable capacitors).

Current research towards the development of smart multifunctional materials with novel, improved properties may be a viable solution for realizing electronic devices and/ or optical modules with greater functionality, faster operating speed, and reduced size. Smart materials are those materials whose optical and electrical properties (transmittance, reflectance, emittance, refractive index, electrical resistivity etc.) can be controlled and tuned by external stimuli (applied field or voltage, incident light, temperature variation, mechanical stress, pressure etc.). In the RF-microwave fields, materials that are relevant towards the fabrication of tuneable components (resistors, capacitors, inductors), can be classified according to their tuneable properties as: tuneable resistivity materials (semiconductors, phase change materials), tuneable permittivity materials (ferroelectrics, 
liquid crystals, pyrochlores, multiferroics) or tuneable permeability materials (ferromagnetics, multiferroics etc.) (Gevorkian, 2008). They can be used to build intelligent components for a broad range of applications: phase shifters/ modulators, delay lines, switches, filters and matching networks, tuneable loads, agile antennas, sensors, detectors etc.

Among the most attractive class of smart materials are those exhibiting a phase transition or a metal- insulator transition. The metal-insulator transition is a large area of research that covers a multitude of systems and materials (chalcogenides, colossal magnetoresistance manganites, superconducting cuprates, nickelates, ferroelectrics, etc.) (Mott, 1968; Edwards et al., 1998). In particular, certain transition metal oxides exhibit such phase transition (Rice \&McWhan, 1970), and among these, the vanadium oxide family $\left(\mathrm{V}_{2} \mathrm{O}_{5}, \mathrm{~V}_{2} \mathrm{O}_{3}, \mathrm{VO}_{2}\right)$ shows the best performance, in particular, presenting a noticeable resistivity change between the two phases. Among these, vanadium dioxide, $\mathrm{VO}_{2}$, has been studied intensely in the last decade because of his large, reversible change in its electrical, optical and magnetical properties at a temperature close to room temperature, of $\sim 68^{\circ} \mathrm{C}$ (Morin, 1959) which makes it a potential candidate for introducing advanced functionalities in RF-microwave devices.

Within the present chapter, we want to offer an insight on the amazing properties of the $\mathrm{VO}_{2}$ materials (focusing on the electrical ones) and to give practical examples of their integration in advanced adaptive devices in the RF-microwave domain, as developed in the last years at the XLIM Institute in collaboration with the SPCTS laboratory, both from CNRS/ University of Limoges, France (Crunteanu et al., 2007; F. Dumas-Bouchiat et al., 2007, 2009, Givernaud et al., 2008).

We will focus in a first step, on the fabrication using the laser ablation (or the pulsed laser deposition -PLD) method of the $\mathrm{VO}_{2}$ thin films, on its structural, optical and electrical characterization (speed and magnitude of phase transition induced by temperature or an external electrical field). In a second step we will show the practical integration of the obtained $\mathrm{VO}_{2}$ films in RF- microwave devices (design, simulation and realisation of $\mathrm{VO}_{2}-$ based switches and tuneable filters in the microwave domain etc.) and we will conclude by presenting the latest developments we are pursuing, namely the demonstration of $\mathrm{VO}_{2}$ based, current-controlled broadband power limiting devices in the RF- microwave frequency domains.

\section{2. $\mathrm{VO}_{2}$ material properties and applications}

As mentioned before, vanadium dioxide is one of the most interesting and studied members of the vanadates family performing a metal-insulator (or, more correctly, a semiconductor to metal phase transition- SMT) (Morin, 1959; Mott, 1968). At room temperature (low temperature state) $\mathrm{VO}_{2}$ is a semiconductor, with a band gap of $\sim 1 \mathrm{eV}$. At temperatures higher than $68^{\circ} \mathrm{C}(341 \mathrm{~K}) \mathrm{VO}_{2}$ undergoes an abrupt transformation to a metallic state, which is reversible when lowering the temperature below $65^{\circ} \mathrm{C} \quad\left(\mathrm{VO}_{2}\right.$ becomes again semiconductor). This remarkable transition is accompanied by a large modification of its electrical and optical properties: the electrical resistivity decreases by several orders of magnitude between the semiconductor and the metallic states while the reflectivity in the near-infrared optical domain increases (Zylbersztejn \& Mott, 1975; Verleur et al., 1968). The reversible SMT transition can be triggered by different external excitations: temperature, optically (Cavalleri et al., 2001, 2004, 2005; Ben-Messaoud et al., 2008; Lee et al., 2007), electrically- by charge injection (Stefanovich et al., 2000; Chen et al., 2008, Kim et al., 2004, 
Guzman et al., 1996, Dumas-Bouchiat et al., 2007) and even pressure (Sakai \& Kurisu, 2008). Recent studies showed that the electrically- and optically- induced transitions can occur very fast (Stefanovich et al., 2000; Cavalleri et al., 2001-2005) (down to $100 \mathrm{fs}$ for the optically- triggered ones (Cavalleri et al., 2005)) and that the transition is more typical of a rearrangement of the electrons in the solid (electron- electron correlations) than it is a an atomic rearrangement (crystalline phase transition from semiconductor monoclinic to a metallic rutile structure).

Although a large number of studies have been devoted to the understanding of the SMT in $\mathrm{VO}_{2}$, there is still no consensus concerning the driving mechanisms of this phase transition (Pergament at el., 2003; Laad et al., 2006, Qazilbash et al., 2007, Cavalleri et al., 2001). The two mechanisms believed to be responsible for the phase transition (the Peierls mechanismselectron-phonon interactions and the Mott-Hubard transition - strong electron-electron interactions) are still elements under debate (Morin, 1959; Mott, 1968; Cavalleri et al., 2001, Stefanovich et al., 200, Pergament et al. 2003, Kim, 2004; Kim, 2008).

The transition temperature of the $\mathrm{VO}_{2}$ layers can be shifted to lower temperatures e.g. by applying an electric field or an incident light beam to a planar two-terminal device (Kim et al., 2004; Lee et al., 2007, Qazilbash et al., 2008, Chen et al., 2008). It is believed that an electric field application to $\mathrm{VO} 2$ or an incident beam influences the electron or holes concentrations resulting in a shift of the transition temperature. According to the MottHubard mechanism (Laad et al., 2006), the SMT transition should be driven by the increase in electron concentration (once the electrons reach a critical concentration, the $\mathrm{VO}_{2}$ pass from semiconductor to metallic). Also, the transition temperature of the $\mathrm{VO}_{2}$ 's SMT can be increased or decreased by doping with metals like W, Cr, Ta or Al (Kitahiro \& Watanabe, 1967; Kim et al., 2007). $\mathrm{VO}_{2}$ has a high voltage breakdown, which can be exploited for transmission of high power levels in microwave devices.

In the last years, en ever increasing number of papers have been published and discussed $\mathrm{VO}_{2}$-based applications, most of which are on microbolometers applications (Yi et al., 2002; $\mathrm{Li}$ et al., 2008), smart thermochromic windows (Manning et al., 2002), spatial light modulators (e.g. Richardson and Coath, 1998; Jiang and Carr, 2004; Wang et al., 2006) or electrical switches development (thin films and single-crystal structures) (e.g. Guzman et al., 1996; Stefanovich et al., 2000; Qazilbash et al., 2007; Kim et al., 2004), but the functioning of the proposed devices is based mainly on the thermal activation of the MIT transition which is far more slow than the purely electric or optical- activated ones (massive charge injection or optical activation). The very few reports concerning the possible integration of $\mathrm{VO}_{2}$ thin films in devices and systems for RF and millimetre wave applications concerns their dielectric properties in this domains (Hood \& DeNatale, 1991), the fabrication of submillimeter -wave modulators and polarizers (Fan et al., 1977), of thermally controlled coplanar microwave switches (Stotz et al., 1999) and numerical simulations of $\mathrm{VO}_{2}$-based material switching operation in the RF-microwave domain (Dragoman et al., 2006). The operating frequency for $\mathrm{VO}_{2}$-based switches was estimated to be beyond $1 \mathrm{THz}$ (Stefanovich et al., 2000), which makes them very attractive for realizing broadband devices in the millimetr-wave domain.

In the last few years we successfully integrated PLD-deposited $\mathrm{VO}_{2}$ thin films in several types of components and more complex devices such as thermally and electrically-activated microwave switches (Crunteanu et al., 2007; Dumas-Bouchiat et al., 2007 and 2009), tunable band stop filters including $\mathrm{VO}_{2}$-based switches (Givernaud et al., 2008) and recently, we 
proposed an original approach for the design and fabrication of self-resetting power limiting devices based on microwave power induced SMT in vanadium dioxide (Givernaud et al., 2009). As an illustration of our current activities towards the integration of $\mathrm{VO}_{2}$ layers in RFmicrowave (RF- MW) devices, we will present the design, fabrication and caracterization of thermally activated MW switches and their integration in a new type of thermally triggered reconfigurable 4-bit band stop filter designed to operate in the 9- $11 \mathrm{GHz}$ frequency range.

\section{PLD deposition and structural, optical and electrical characterization of the $\mathrm{VO}_{2}$ thin films}

Several deposition methods have been proposed for fabrication of $\mathrm{VO}_{2}$ thin films: sputtering, evaporation pyrolysis or chemical reaction techniques (Hood \& DeNatale, 1991; Stotz et al., 1999; Manning et al., 2002; Li et al., 2008 etc.). According to the multivalency of vanadium ion and its complex oxide structure (Griffiths \& Eastwood, 1974), numerous phases with stoechiometries close to $\mathrm{VO}_{2}$ can exist (from $\mathrm{V}_{4} \mathrm{O}$ to $\mathrm{V}_{2} \mathrm{O}_{5}$ ) and the synthesis of phase pure $\mathrm{VO}_{2}$ thin films is an important challenge. Reactive pulsed laser deposition (PLD) is a suitable technique for obtaining high-purity oxide thin films (Chrisey \& Hubler, 1994; Eason, 2007), very well adapted for obtaining the stoichiometric $\mathrm{VO}_{2}$ layers. However, careful optimisation of the working parameters is necessary to obtain thin films of the pure $\mathrm{VO}_{2}$ stabilized phase without any post-treatment.
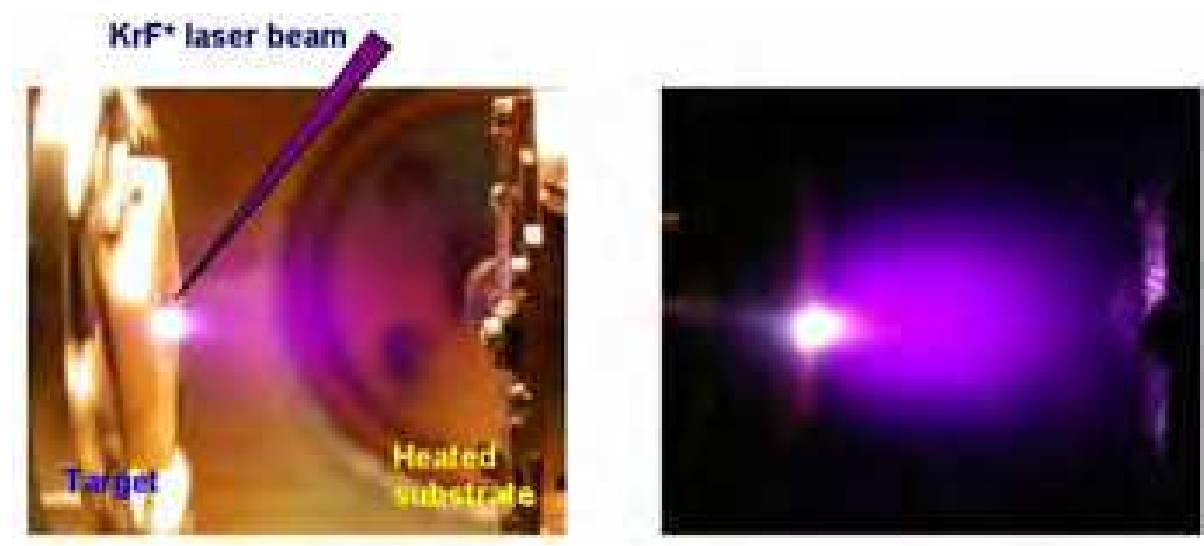

Fig. 1. Photography of the PLD set-up showing schematically the inside of the deposition chamber (left-hand side) and the expansion of the plasma plume towards the substrate after the laser pulse (right-hand side).

In our case, $\mathrm{VO}_{2}$ thin films were deposited using reactive pulsed laser deposition from a high purity grade $(99.95 \%)$ vanadium metal target under an oxygen atmosphere. The experimental set-up (picture shown in Fig.1) was described elsewhere (Dumas-Bouchiat et al., 2006) and is based on an excimer $\mathrm{KrF}$ laser (with a wavelength of $248 \mathrm{~nm}$ and a pulse duration of $25 \mathrm{~ns}$ ), operating at a repetition rate of $10 \mathrm{~Hz}$. The laser beam is focused on a rotating target in order to obtain fluences (i.e. energies per irradiated surface unit) in the order of 5 to $9 \mathrm{~J} / \mathrm{cm}^{2}$. The plasma plume expands in the ambient oxygen atmosphere (total 
pressure in the chamber maintained at $2 \times 10^{-2}$ mbar). Since it has a relatively low lattice parameter mismatch $(4.5 \%)$ as compared to $\mathrm{VO}_{2}$ monoclinic phase, monocristalline $\mathrm{Al}_{2} \mathrm{O}_{3}(\mathrm{C})$ is a good candidate to deposit mono-oriented $\mathrm{VO}_{2}$ films (Garry et al., 2004). The substrate is heated by an halogen lamp at about $500^{\circ} \mathrm{C}$ and the deposition duration is changing from 10 to 45 minutes leading to thickness in the range $100-600 \mathrm{~nm} . \mathrm{VO}_{2}$ thin films have been also deposited on sapphire R-type substrates $\left(\mathrm{Al}_{2} \mathrm{O}_{3}(\mathrm{R})\right)$, quartz or $100 \mathrm{Si}$ substrates (bare or oxidized with a $1-\mu \mathrm{m}$ thick layer of $\mathrm{SiO}_{2}$ ).

Irrespective on the substrate we used, the obtained films show a smooth surface with very low-density or no particulates at all, as indicated by scanning electron microscopy analysis, see Fig. 2a. Their morphology (as revealed by atomic force microscopy, AFM, Fig. 2b) consists of compact quasispherical crystallites with typical dimensions (root mean square roughness) between 5 and $15 \mathrm{~nm}$. The non-dependence of film morphology on the substrate nature may be an indication that the growth mechanism is governed mainly by the laser beam/ target interaction.

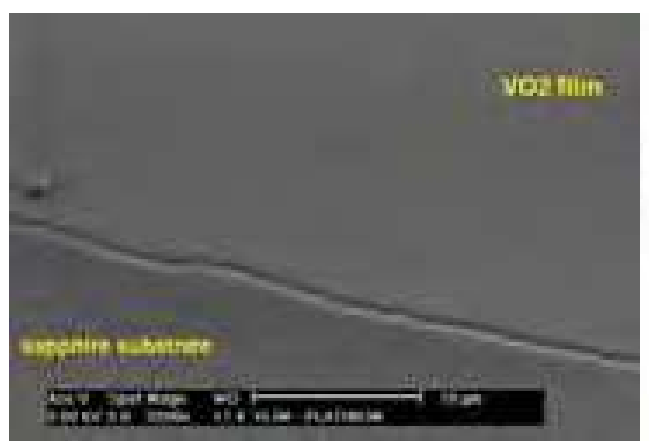

a

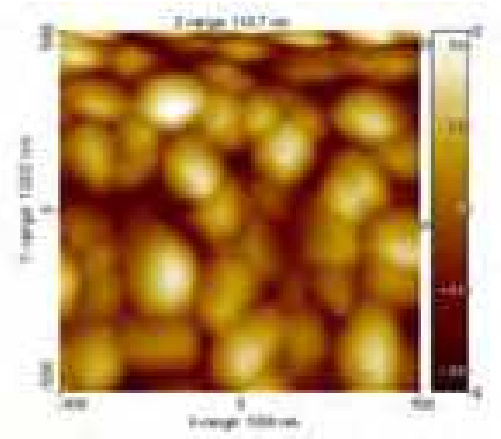

b.

Fig. 2. a) SEM image of a $\mathrm{VO}_{2}$ thin film growth on a sapphire substrate showing a smooth surface and b) AFM image obtained on a $\mathrm{VO}_{2}$ film (75-nm thickness) onto a sapphire $\mathrm{R}$ substrate showing compact crystallites.

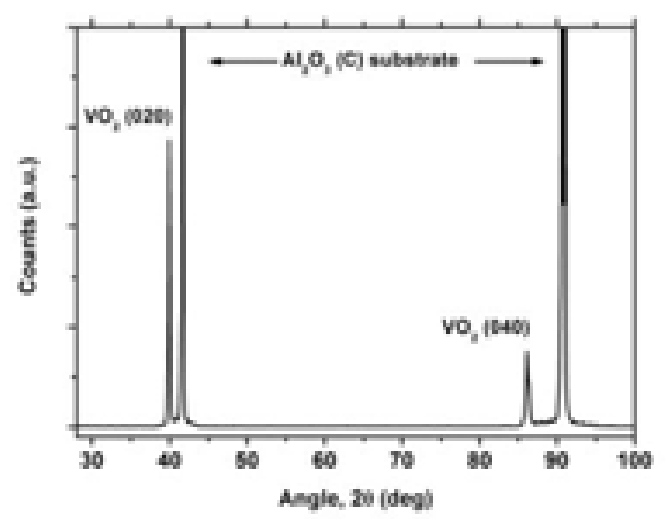

Fig. 3. Typical XRD scan for a 200-nm thick $\mathrm{VO}_{2}$ thin film deposited on an $\mathrm{Al}_{2} \mathrm{O}_{3}(\mathrm{C})$ substrate showing characteristic peaks $\left((020)\right.$ and (040) of the monoclinic phase of $\mathrm{VO}_{2}$. 
X-Ray diffraction -XRD investigations (in $\theta, 2 \theta$ configuration) performed on $\mathrm{VO}_{2} / \mathrm{Al}_{2} \mathrm{O}_{3}(\mathrm{C})$ thin films reveal two peaks located near $40.2^{\circ}$ and $86.8^{\circ}$ corresponding respectively to the (020) and (040) planes of the monoclinic $\mathrm{VO}_{2}$ phase. In certain cases, and especially for amorphous substrates $\left(\mathrm{SiO}_{2} / \mathrm{Si}\right.$ substrates), depending on the deposition parameters, a peak appears near $28^{\circ}$ corresponding to the (011) planes of $\mathrm{VO}_{2}$ with an orthorhombic structure (Youn et al., 2004).

\subsection{Temperature-induced SMT of $\mathrm{VO}_{2}$ thin films}

For the obtained $\mathrm{VO}_{2}$ films we recorded the variation of their electrical optical and properties (resistivity and optical transmission variation) with the applied temperature in order to rapidly assess the amplitude of their temperature-activated SMT transition.

The electrical resistance/ resistivity of the $\mathrm{VO}_{2}$ thin films was recorded in the $20-100^{\circ} \mathrm{C}$ temperature range using a two-terminal device (two metallic contacts deposited nearby on a rectangular $\mathrm{VO}_{2}$ pattern). A typical resistance hysteresis cycle (heating- cooling loop) of a 200-nm thick $\mathrm{VO}_{2}$ thin films deposited on a C-type sapphire substrate can be observed in Fig. 4 (the VO2 pattern between the two measurements electrodes was, in this case, $70 \mu \mathrm{m}$ long $\times 45 \mu \mathrm{m}$ wide and $200 \mathrm{~nm}$ thick). One may observe a huge change in its resistance as the temperature is cycled through the phase transition $\left(\mathrm{R} \sim 450 \mathrm{k} \Omega\right.$ at $20^{\circ} \mathrm{C}$ down to $\mathrm{R} \sim 75 \Omega$. at $100^{\circ} \mathrm{C}$ ). The width of the hysteresys curve (heating- cooling cycle) is very small: the transition occurs in the $72-74^{\circ} \mathrm{C}$ range when heating the sample (transformation from semiconductor to metal) and in the $65-68^{\circ} \mathrm{C}$ range when cooling down at room temperature, and is witnessing on the high quality of the obtained material.

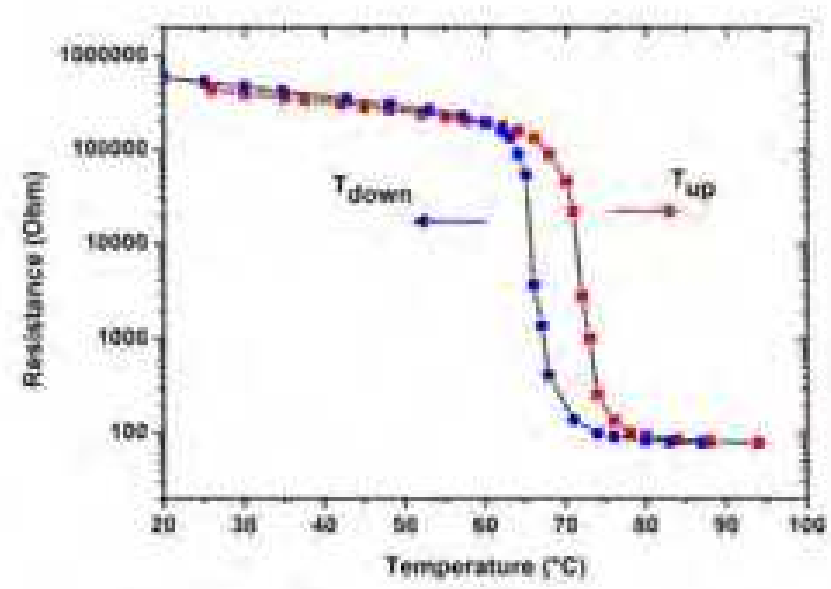

Fig. 4. Resistance variation with temperature for a $\mathrm{VO}_{2}$ film (two terminal device of $70 \mathrm{~mm}$ long, $45 \mathrm{~mm}$ wide and $200 \mathrm{~nm}$ thick) fabricated by PLD on a C-type sapphire substrate

The optical transmission measurements of $\mathrm{VO}_{2}$ layers on different substrates as a function of the temperature were done in the UV-visible- mid-IR regions of the spectrum using a Varian Carry 5000 spectrophotometer equipped with a sample heater. They were recorded for different temperatures in the $20-100^{\circ} \mathrm{C}$ domain. As observed on Fig. 5, the $\mathrm{VO}_{2}$ films 
deposited on $\mathrm{Al} 2 \mathrm{O} 3(\mathrm{R})$ and on $\mathrm{SiO}_{2} / \mathrm{Si}$ substrates showed a very sharp phase transition witnessing of abrupt change (transmission change factors between 4 and 8 ) of its optical properties (drastic modification of its refractive index and absorption coefficient). One may notice on the graph on Fig. 5a that the temperature- dependent transmission curves intersect in a particular point, the isosbestic point (at $\sim 850 \mathrm{~nm}$ ) where the transmittance is constant for all temperatures (Qazilbash et al., 2007).
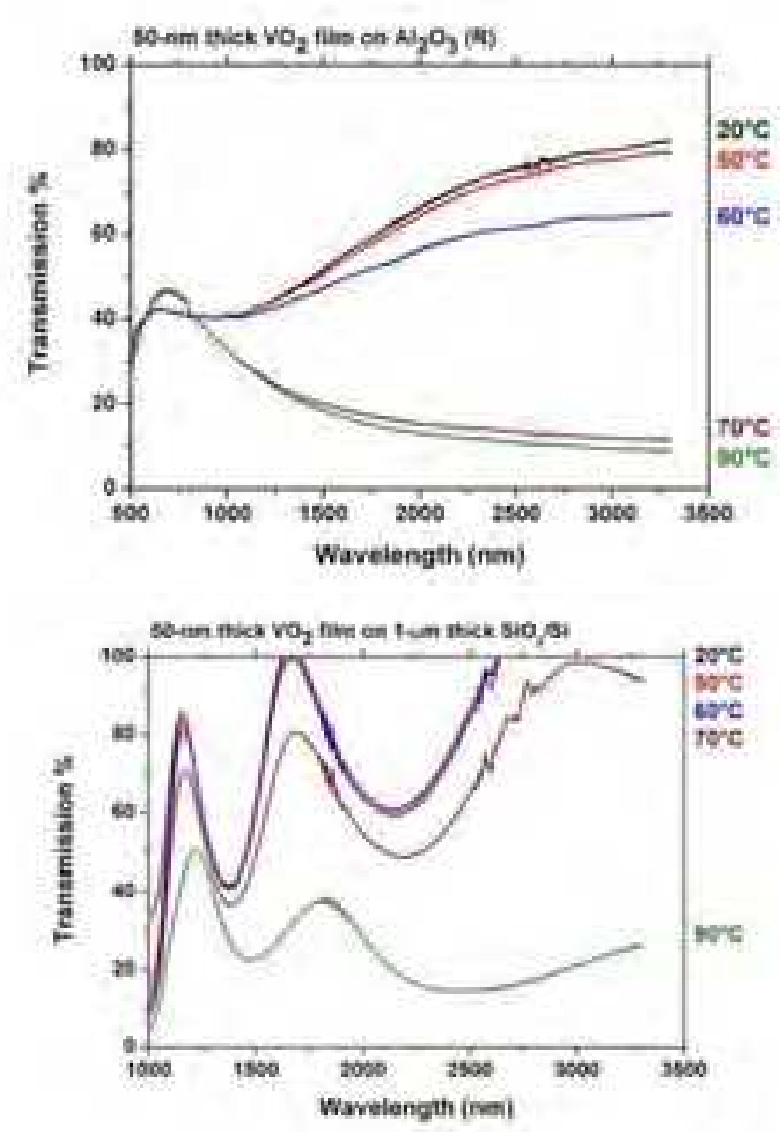

a.

b.

Fig. 5. Optical transmission spectra vs. temperature for 50-nm thick $\mathrm{VO}_{2}$ films made by PLD on R-type sapphire substrates (a) and $1-\mu \mathrm{m}$ thick $\mathrm{SiO}_{2} / \mathrm{Si}$ substrate (the oscillations visible on these spectra are interference patterns due to the $\mathrm{SiO}_{2} / \mathrm{Si}$ stack layers)(b).

We also investigated the reflectivity variation of the $\mathrm{VO}_{2}$ films versus the temperature. Typically, a substrate covered with a $\mathrm{VO}_{2}$ thin layer was placed on a heating stage and the optical power of a reflected fiber laser beam (at $1550 \mathrm{~nm}$ ) directed at almost normal incidence onto the film surface was recorded during temperature variation in the $20-100^{\circ} \mathrm{C}$ domain. On Fig. 6 is presented a typical hysteresys cycle of film's reflectivity (heatingcooling cycle). The $\mathrm{VO}_{2}$ films showed a very sharp, abrupt phase transition that occurs 
irrespective of the used substrate or of their thickness. As in the case of the electrical resistivity measurements, the width of the hysteresys curve is very small.

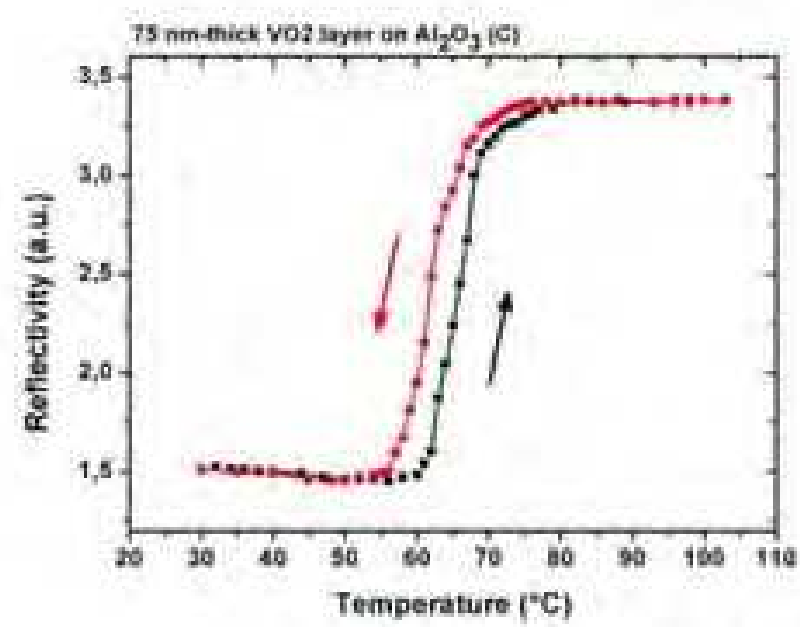

Fig. 6. Hysteresis cycle of reflectivity (at $1550 \mathrm{~nm}$ ) vs. temperature for a $75-\mathrm{nm}$ thick $\mathrm{VO}_{2}$ film made by PLD on C-type sapphire substrate showing the sharp phase transition of the $\mathrm{VO}_{2}$ material.

\subsection{Electrically- induced SMT of $\mathrm{VO}_{2}$ thin films}

The proof of concept of thermally induced SMT of $\mathrm{VO}_{2}$ thin films for realising microwave (and optical) switching devices shown above represents already an innovative, interesting field of research both from theoretically and practical points of view. However, the electrically driven SMT of the $\mathrm{VO}_{2}$ material will results in more practical devices (without the need of a additional temperature source for the phase transition activation) that, theoretically, can be activated several orders of magnitude faster (Mott, 1968; Cavalleri et al., 2001; Stefanovich et al., 2000; Kim et al., 2004).

We therefore initiated investigations for evaluating the electrically induced phase transition of $\mathrm{VO}_{2}$ thin films integrated in two-terminal switching devices. The $\mathrm{VO}_{2}$ pattern is included in an electrical circuit (Fig. 7a) with a c.c. voltage source (applied voltage, $V_{\text {ap }}$ ), an amperemeter (measuring the current in the circuit, I) and a resistor (Rs, with typical values between 100 and $1500 \Omega$ ) for limiting the overall current in the circuit since high values of the current may damage the $\mathrm{VO}_{2}$ switch. The first results $\left(\mathrm{I}-\mathrm{V}_{\mathrm{ap}}\right.$ and $\mathrm{I}-\mathrm{V}_{\mathrm{VO} 2}$ characteristics $)$ of the electrically actuated $\mathrm{VO}_{2}$ - based two-terminal device (rectangular pattern, $40-\mu \mathrm{m}$ long, $95-\mu \mathrm{m}$ wide and $200 \mathrm{~nm}$ thick) are presented on Figs. 7 b, c. It may be seen that at aiven threshold voltage ( $\mathrm{V}_{\text {ap }}$ between 11 and $14 \mathrm{~V}$ for the c.c. voltage source, and $\mathrm{V}_{\mathrm{VO} 2} \sim 10.5$ to 13 $\mathrm{V}$ for the voltage on the $\mathrm{VO}_{2}$ circuit, depending on the Rs value) the current increase abruptly, indicating that the resistivity of the $\mathrm{VO}_{2}$ layer decreased. This phenomenon is indicative on the onset of the phase transition, $\mathrm{VO}_{2}$ passes from a high resistive state (semiconductor) in a low-resistive one (it becomes metallic). 


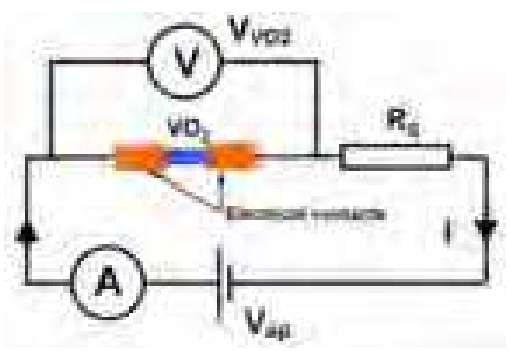

a.

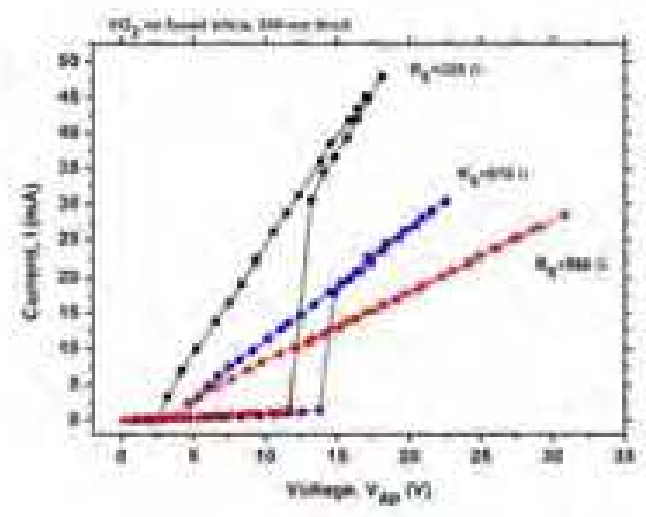

b.

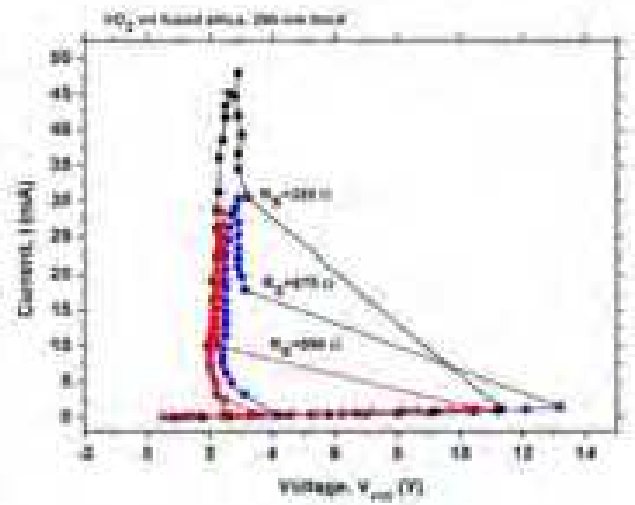

c.

Fig. 7. a) Electrical circuit set-up for investigating the Electrically- induced SMT transition of a two terminal switching device based on a $\mathrm{VO}_{2}$ thin film (200-nm thick on C-type sapphire); b) $I-V_{\text {ap }}$ hysteresis characteristic as the $V_{\text {ap }}$ is swept between 0 and maximum of $30 \mathrm{~V}$ and backwards and c) the typical S-shape of the I- $\mathrm{V}_{\mathrm{VO} 2}$ characteristic of the device.

The nonlinear, S-shaped, negative differential resistance (NDR) $\mathrm{I}_{\mathrm{V}} \mathrm{V}_{\mathrm{VO} 2}$ characteristic, typical for the $\mathrm{VO}_{2}$ material (and whose shape can be tuned with external applied temperature) is of high interest from the viewpoint of fundamental physics as well as of a broad range of applications (NDR based oscillators, transistors, filters etc.). 
The device remains in the activated state as long as the voltage or the current is maintained in the circuit. For evaluating the switching time of the electrically induced transition we used a similar activation schema (Fig. 8a) but including an a.c. voltage actuation with a square-type waveform (voltage pulses for which the temporal width were varied from 1 to $20 \mu \mathrm{m})$.

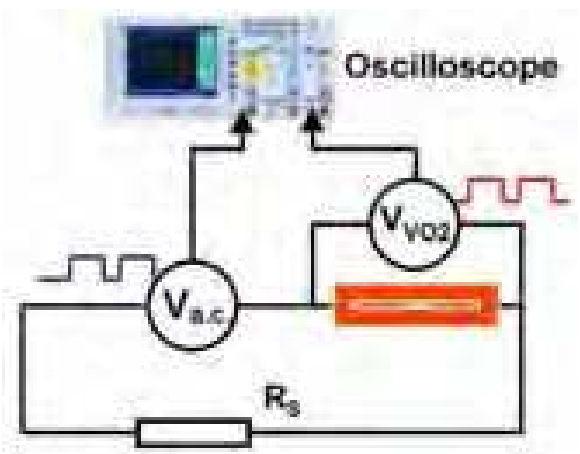

a.

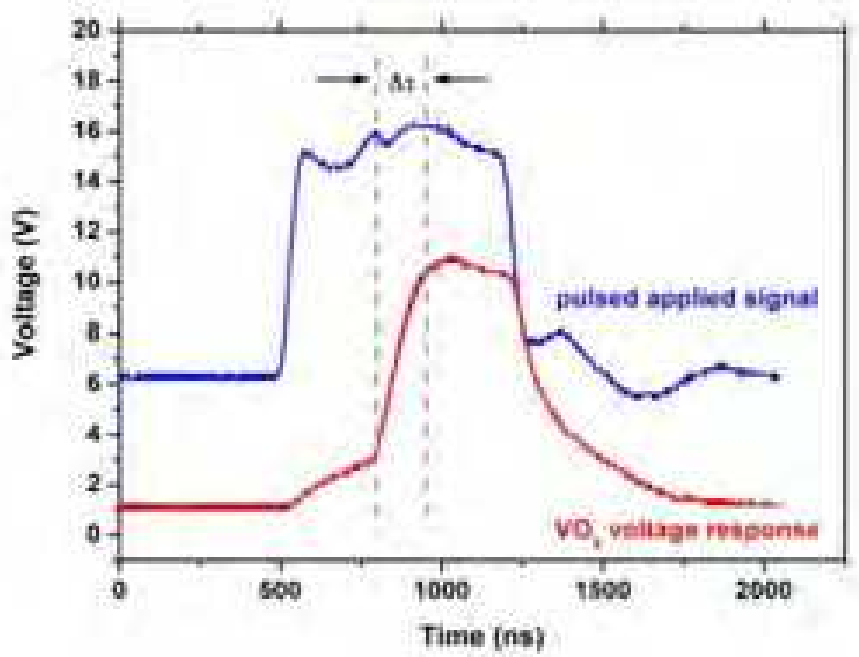

b.

Fig. 8. a) Set-up for electrical activation of the SMT transition and evaluation of the switching time of a $\mathrm{VO}_{2}$-based two-terminal switch $\mathrm{b}$ ) applied squared waveform (16 V amplitude, $1.5 \mu \mathrm{s}$ in width) and the voltage variation through the VO2 switch (in series with a resistor having $R_{S}=278 \Omega$ ) showing installation of the VO2's SMT with activation times $\Delta \tau$ which varies between 100 and 250 ns.

As indicated in Fig. 8 b, c, preliminary results indicate switching times values as low as several hundreds of nano-seconds, which are, however, situated well above the electronically induced $\mathrm{VO}_{2}$ transition (supposed to occur in the ps domain). 
Although the theoretical calculations for a current-induced temperature initiation of the SMT transition (by the Joule heating effect) on the tested device lies in the order of the micro-second scale time (higher than the switching times we recorded), it is prematurely to asses on a purely electrical-induced phase transition (by charge injection). More likely we recorded a switching time describing a mixture of the two potentially present mechanisms (Joule effect heating and charge injection). Nevertheless, the key point of these experiments is that the switching time values are better than those of devices employing fast MEMSbased solutions (Lacroix et al., 2007) and not far from the switching times values of the semiconductors currently used in millimeter domain-switching devices.

We should point out that the electrical activation of $\mathrm{VO}_{2}$ thin films is also accompanied by changes in their optical properties, easily perceived using optical microscopy and recorded using a CCD camera, as reflectivity change periodically with the applied a.c. signal. These findings are currently exploited in our group for fabrication of variable reflectivity micro mirrors and attenuators in the optical domain for high-speed modulators in novel laser systems (results not reported here).

To resume the preliminary results presented above we may say that the $\mathrm{VO}_{2}$ is a very interesting and exciting phase transition material. Its electrical and optical properties may be tuned in a static or dynamical way by external factors such as the temperature or an applied electrical field or voltage. These results were further exploited for the realization of rapid electrically switching of microwave coplanar waveguide (CPW) lines or the fabrication of band-stop-type MW filters.

\section{Integration of $\mathrm{VO}_{2}$ thin films in microwave switches and filters}

The enormous resistivity change ( 3 to 4 order of magnitude) of the $\mathrm{VO}_{2}$ material undergoing the SMT induced by the temperature or by an applied voltage was exploited to fabricate and characterize simple microwave switches based on a coplanar microwave waveguide integrating $\mathrm{VO}_{2}$ thin films. We obtained temperature activated switching functions (in both shunt and series configurations) with relatively low losses and more than $25 \mathrm{~dB}$ transmission variations between the ON/OFF states, on a very large bandwidth $(50 \mathrm{MHz}-$ 35 GHz) (Crunteanu et al., 2007; Dumas-Bouchiat et al., 2009). The concept was successfully implemented for more complex devices, such as tuneable band stop filters operating around $10 \mathrm{GHz}$ in the microwave frequency domain (Givernaud et al., 2008).

\subsection{Microwave switching based on $\mathrm{VO}_{2}$ films two terminal devices}

In the followings we will present a novel concept of $\mathrm{VO}_{2}$-based electrical switch by using the discrete (and local) thermal activation of a $\mathrm{VO} 2$ two-terminal device using a miniature heating element. The micro-heater is based on a thin-film resistor fabricated from a Nidoped tetrahedral carbon layer (Ni:ta-C). Nickel-doped ta-C layers are currently used in our laboratory and efficiently integrated in radio frequency micro electro mechanical systems (RF MEMS) and in other tunable components (Orlianges et al., 2005). These thin films allows the realization of localized, high value, planar, easily patterned resistances, leading to significant improvement of insertion losses of MEMS switches integrated in electronic devices. Such thin-film resistors are often used under high value of electrical current, which generate important heating of these devices. Our previous investigations on ta-C layers doped with 5\%-30\% wt. Ni showed that the layers preserve their integrity for current 
densities as high as $1.5 .10^{5} \mathrm{~A} / \mathrm{cm}^{2}$ (Orlianges et al., 2004). This caracteristic of the Ni:ta-C layers can be exploited for fabrication of localized, micrometer-range heating elements which may be used to discretely activate $\mathrm{VO}_{2}$-based two terminal switches (the important ammount of heat generated into the Ni:ta-C layers will be transmitted to the VO2 patterns placed underneath). The amount of the heat generated by the micro heater element can be adjusted by changing the dimensions and the doping level of the Ni:ta-C pattern.

The design of a fabricated $\mathrm{VO}_{2}$-based switch which can be activated by the heat generated in a Ni:ta-C thin film is presented in the optical micrscope image on Fig. 9 a.

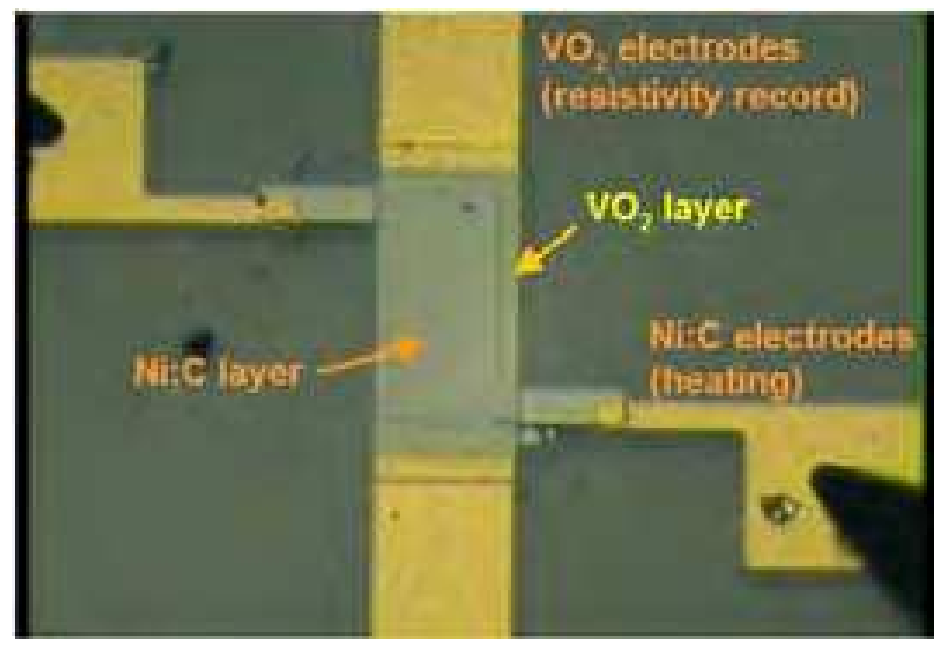

a.
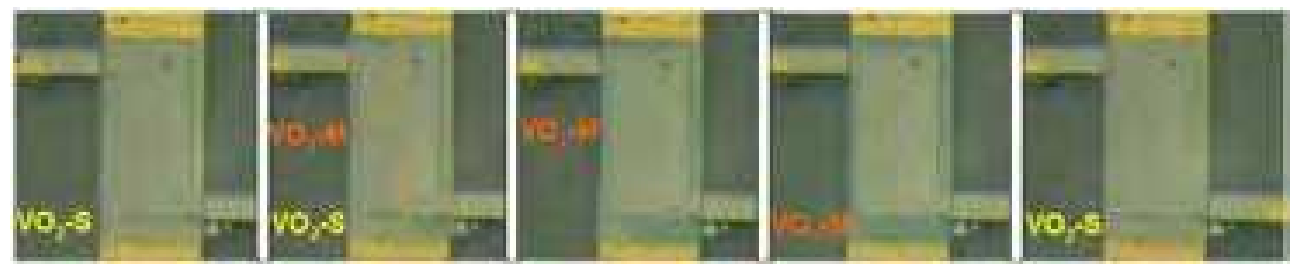

b.

Fig. 9. a) Optical microscopy image of a $\mathrm{VO}_{2}$-based two terminal switch (400- $\mu \mathrm{m}$ long, 200$\mu \mathrm{m}$ wide, 200-nm thick pattern between two gold electrodes) which is activated by the current induced heating in a $10 \%$ wt. Ni:ta-C pattern situated above it $(340-\mu \mathrm{m}$ long, $150-\mu \mathrm{m}$ wide and 100-nm thick) and b) optical images showing the sequential activation (phase transition) of the underneath $\mathrm{VO}_{2}$ layer when applying periodical squared voltage pulses (80V amplitude, $1 \mathrm{~Hz})$ on the Ni:ta-C pattern $\left(\mathrm{VO}_{2}-\mathrm{S}\right.$-semiconducting phase and $\mathrm{VO}_{2}-\mathrm{M}$ - the mettalic state of the $\mathrm{VO}_{2}$ layer.

The device was fabricated in a clean room environment using classical micro fabrication technology. The 200-nm thick $\mathrm{VO}_{2}$ films were deposited using PLD from a vanadium target in oxygen atmosphere on C-cut sapphire substrates (500- $\mu$ m thickness) in the conditions described above. The VO2 layers were further patterned using optical lithography and wet 
etching for defining the rectangular patterns. It follows the partial masking of the substrate with a photoresist layer for deposition of the Ni:ta-C layers ( 100-nm thick) precisely above the $\mathrm{VO}_{2}$ patterns (the lift-off technique). The nickel doped ta-C films have been deposited under high vacuum by $\mathrm{KrF}$ laser ablation of alternating $\mathrm{C}$ and $\mathrm{Ni}$ targets at ambient temperature (Orlianges et al., 2004). At the end, we fabricated the metallic electrodes: a Ti/ $\mathrm{Au}$ layer (6-nm/ 1- $\mu \mathrm{m}$ thick $\mathrm{Ti}$ is used as adhesion layer) is deposited using thermal evaporation; the shape of the electrodes are defined by photoresist masking using optical lithography followed by the partial wet etching of the $\mathrm{Ti} / \mathrm{Au}$ layer. We tested different pattern dimensions for the VO2 switch (from 200 to $400-\mu \mathrm{m}$ long and 100 to $200-\mu \mathrm{m}$ wide) and for the heating Ni:ta-C thin film resistors (100 to 350- $\mu \mathrm{m}$ long and 50 to $150-\mu \mathrm{m}$ wide).

For the device shown in Fig. 9 a $\left(\mathrm{VO}_{2}\right.$ pattern of $400-\mu \mathrm{m}$ long, 200- $\mu \mathrm{m}$ wide, 200-nm thick pattern between the two metallic electrodes), when applying a current (up to $10 \mathrm{~mA}$ ) to the Ni:ta-C heating element (340- $\mu \mathrm{m}$ long, $150-\mu \mathrm{m}$ wide, with an overall resistance of $\sim 11 \mathrm{k} \Omega$ ) the heat generated in the micro-heater will dissipate to the underneath $\mathrm{VO}_{2}$ layer and will raise its temperature above the $\mathrm{SMT}^{\prime} \mathrm{s}$ transition temperature (around $68^{\circ} \mathrm{C}$ ). The $\mathrm{VO}_{2}$ will therefore pass from a semiconductor to a metal state. As in the case of an optical switch, the transition is easily observed using the optical microscopy as clear changes of the $\mathrm{VO}_{2}$ layer's reflectivity. These sequential reflectivity changes were recorded using a CCD camera (Fig. 9 b) as we applied to the micro heating layer (Ni:ta-C) a pulsed periodical squared signal ( $80 \mathrm{~V}$ amplitude, $1 \mathrm{~Hz}$ ). The onset of the $\mathrm{VO}_{2}$ 's phase transition was also recorded electrically by monitoring the resistance of the two-terminal device as a c.c. voltage was progressively applied on the Ni:ta-C heater (Fig. 10).

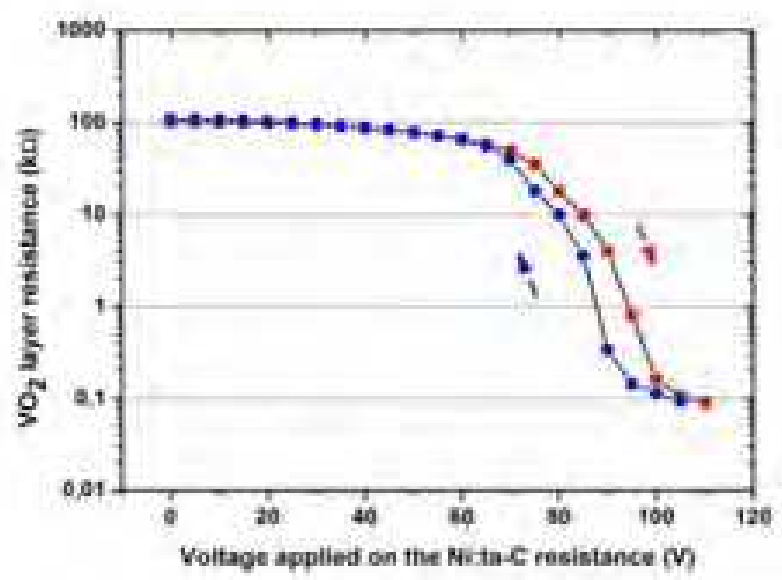

Fig. 10. $\mathrm{VO}_{2}$ 's two-terminal device transversal resistance versus the voltage applied on the Ni:ta-C heating resistance: heating phase (red), cooling phase (blue)

One may easily noticed the great variation of the $\mathrm{VO}_{2}$ 's resistivity (onset of the SMT) as the $\mathrm{Ni}$ :ta-C element dissipate the resistive heating. Work is in progress in order to simulate the heating transfer processes in the overall device, which will allow for optimum design in term of lowering the power consumption. The obtained thermal switching device allows for discrete, localized activation of micrometer-sized $\mathrm{VO}_{2}$ patterns and may be easily integrated 
in more complex functions (filtering module), as it will be demonstrated in the next subchapter.

\subsection{Design and performances of tuneable band-stop filters including $\mathrm{VO}_{2}$-based switches.}

We used the large resistivity change of the device presented above for realising a tuneable 4pole band stop filter designed to operate in the $9-11 \mathrm{GHz}$ frequency range with a large signal attenuation in the attenuated band (> $20 \mathrm{~dB}$ ) (Givernaud et al., 2008). The filter (realised in the micro strip geometry) consists in a $50 \Omega$ transmission line coupled with four U-shaped resonators (Fig. 11). Each resonator is "closed" by a $\mathrm{VO}_{2}$-based pattern which can be independently activated from the semiconductor to the metallic phase by the Ni:ta-C thin film micro heater. At room temperature, the $\mathrm{VO}_{2}$ patterns are insulating $\left(\mathrm{VO}_{2}\right.$ pattern resistance of $98 \mathrm{k} \Omega$ ), the resonators are "opened" and each of them will introduce a specific absorption band in the transmission spectrum of the filter (Fig. 13 a). The design of the filter was done using the ADS Momentum simulator and the dimensions and position of each of the resonators (position and distance from the transmission line) was optimised in such a way that the sum of each absorption band result in an broad absorption band between 10 and $11 \mathrm{GHz}$ while maintaining a high signal attenuation $(>20 \mathrm{~dB})$, as visualized in Fig. $13 \mathrm{a}$.

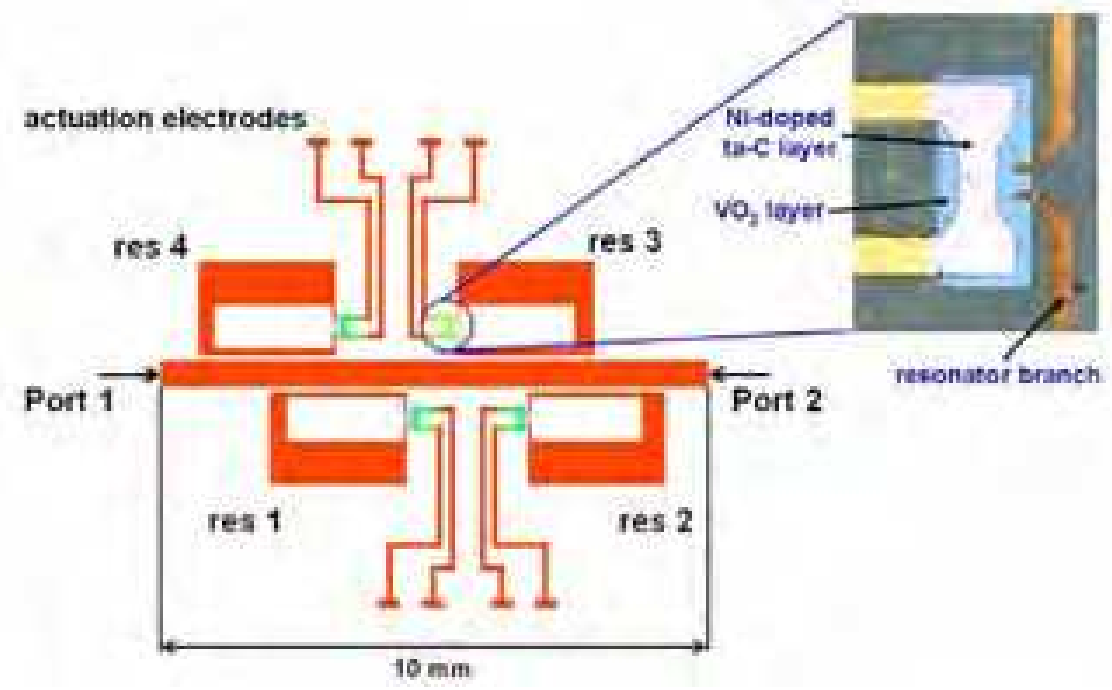

Fig. 11. Design of the four-pole band stop filter that can be discretely tuned by thermally activated each of the $\mathrm{VO}_{2}$-charged resonators; the insert shows the design of the $\mathrm{VO}_{2}$-based switch (activated by a Ni:ta-C pattern) which was adapted to the filter's design.

When individually activated, the metallic $\mathrm{VO}_{2}$ pattern (resistance of $78 \Omega$ ) will electrically closed its corresponding U-shaped resonator. The design of the filter (dimensions, resonators dimensions etc.) was done in such a way that the absorption band of the activated resonator would be then shifted far away from the operation frequency band of the filter. The response of the filter will change: shift of the absorption band (tuneability), 
bandwidth decrease and even disappearance of the attenuation band (Fig. $13 \mathrm{~b}$ when all the resonators are activated). This concept was already applied (Givernaud et al., 2008; DumasBouchiat et al., 2009) and results in innovative, discretely tuned filtering functions in the microwave domain.

The filter was fabricated in a clean room environment using classical micro fabrication technology in the conditions described elsewhere (Givernaud et al., 2008). The obtained device was placed using a conductive epoxy paste (for defining the ground plane of the micro strip geometry) in a metallic package and the transmission line ends are electrically connected to SMA-type connectors for measurements (Fig. 12).

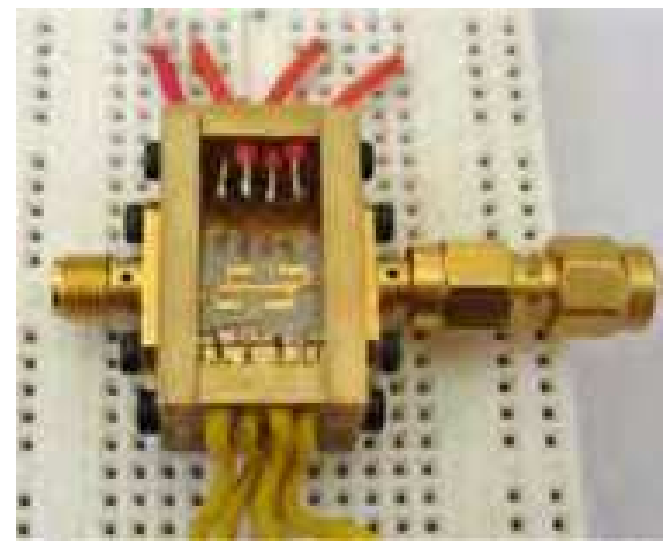

Fig. 12. Photography of the realized $\mathrm{VO}_{2}$-based four-pole filter inserted in a metallic housing and connected to SMA connectors for measuring its response.

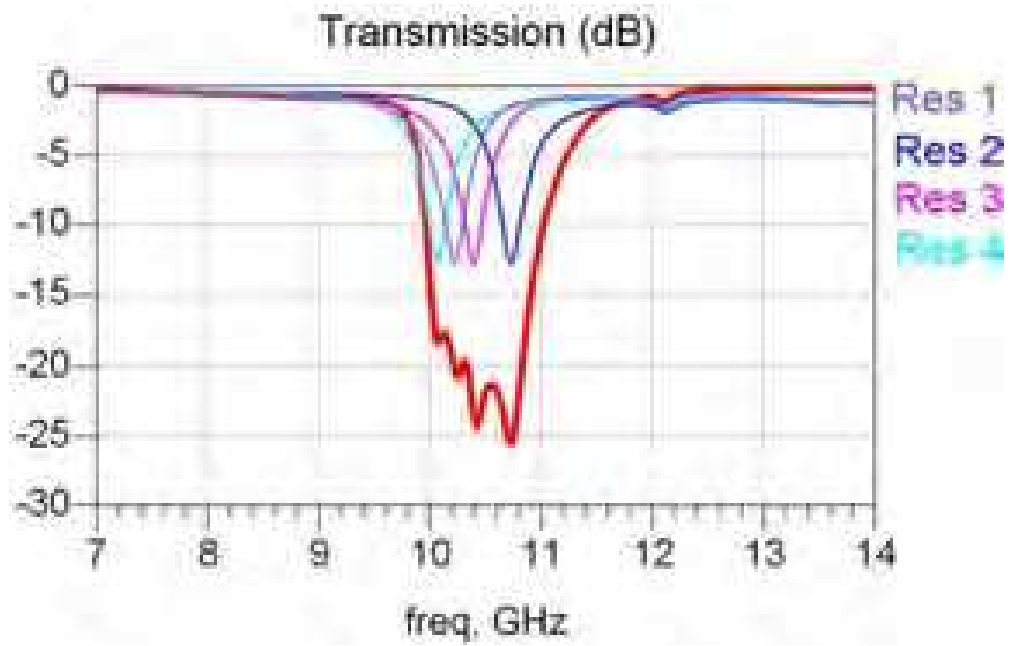

a. 


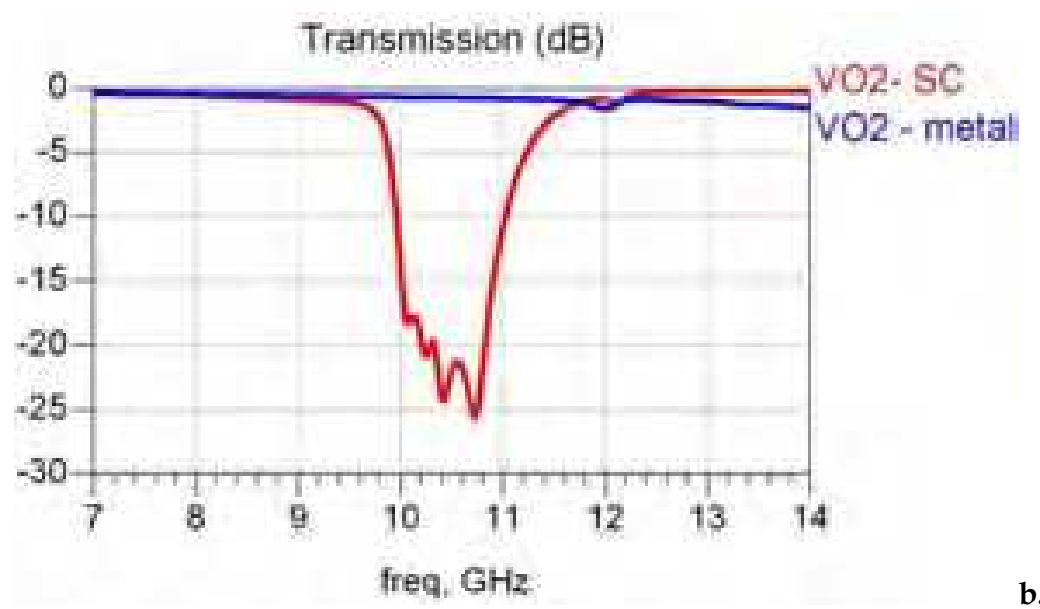

Fig. 13. a) ADS Momentum simulation of the S21 transmission parameter for the overall filter (red curve), showing the absorption band contributions of each resonators and $b$ ) the simulated $\mathrm{S}_{21}$ transmission parameter of the four-pole band stop filter when the $\mathrm{VO}_{2}$-based resonators are "opened" (red curve, $\mathrm{VO}_{2}-\mathrm{SC}$ ) and "closed" (blue curve, $\mathrm{VO}_{2}$-metal).

The response of the packaged filter was measured using a calibrated four-ports vectorial network analyser (VNA, HP $8722 \mathrm{ES}$ ) in the 7 to $14 \mathrm{GHz}$ frequencies range. The measured response of the filter is presented on the graph in Fig. 14 in the two extreme cases: when all the $\mathrm{VO}_{2}$ patterns are insulating, red curve, and when all the $\mathrm{VO}_{2}$ patterns are activated by the Ni:ta-C micro-heating elements.

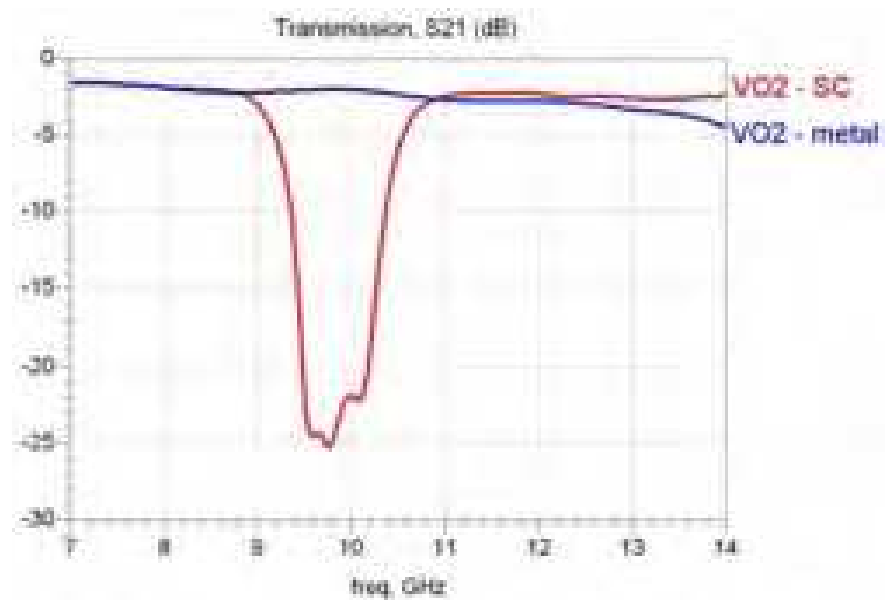

Fig. 14. Measured responses (transmission S21 parameter) of the four pole band stop filter, at room temperature (red curve VO2-SC) and activated (blue curve, VO2-metal, all of the resonators are activated) 
One may notice a good agreement of the measured filter responses with the simulations (Fig. 13b). Although the operation band is shifted towards the low frequencies this can be easily corrected for future design by taking into account the deviation from the theoretical values of the materials constants used for the simulation response and by taking care to the micro fabrication tolerances). The tunability of the filter can be demonstrated by individual activation (using the micro-heaters) of specific resonators. When the $\mathrm{VO}_{2}$-switch of two resonators, for example resonators 1 and 4 (as marked on the Fig. 11) becomes low resistive $\left(\mathrm{VO}_{2}\right.$ in the metallic state), the rejection band of the filter will change: its central frequency will shift towards higher frequencies, at $10.6 \mathrm{GHz}$ and its full width at half maximum (FWHM) will lower from $\sim 1 \mathrm{GHz}$ to about $0.4 \mathrm{GHz}$, as shown for the simulated response on Fig. 15 a. A similar behaviour was recorded for the measured response (Fig. 15 b) although the decreasing of the rejection bandwidth was less marked.

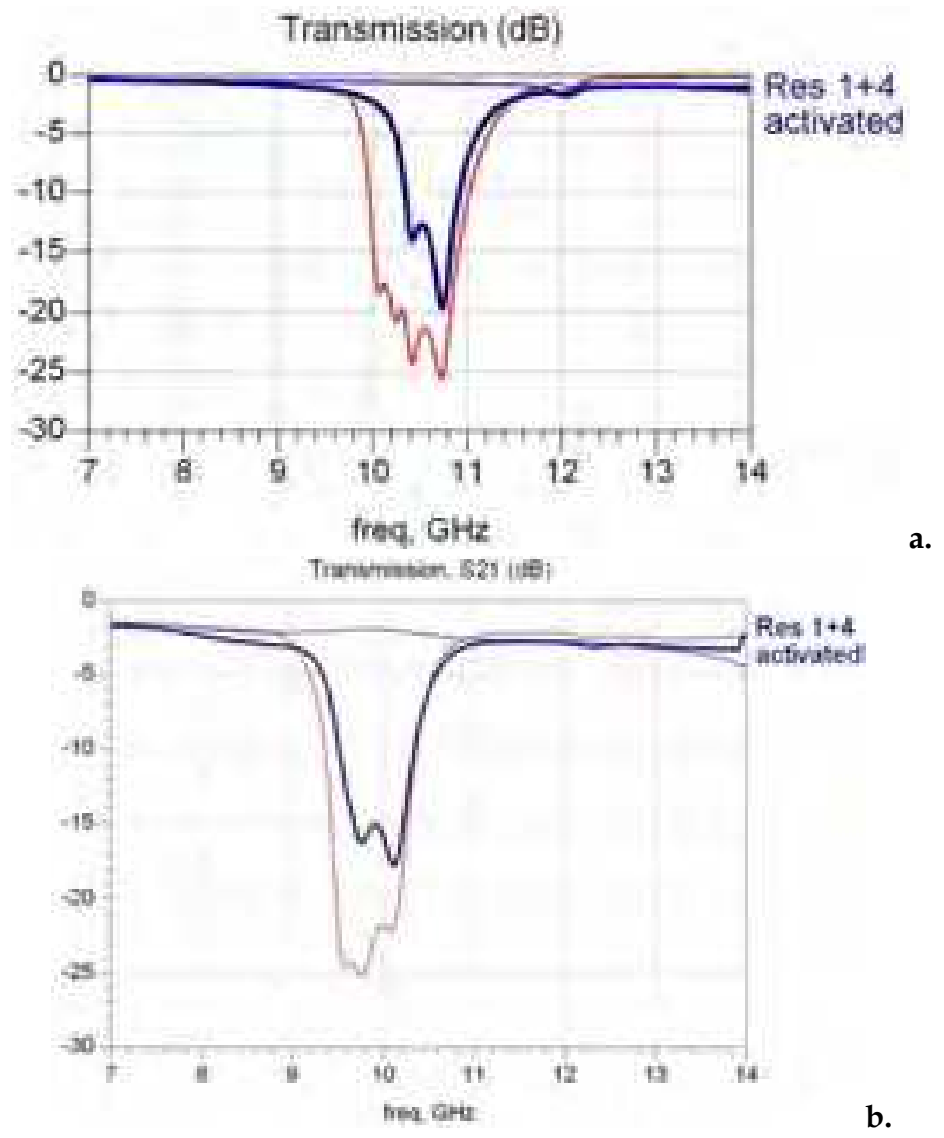

Fig. 15. ADS Momentum simulation (a) and measurement results (b) of the four-pole band stop filter when resonators 1 and 4 (as indicated on the Fig. 11) are simultaneously activated (blue curve, compared with the initial response of the non-activated filter, the red curve). 
The simultaneously activation of two others resonators (those numbered 2 and 3 on Fig. 11), leads to a displacement of the central frequency of the rejection band of the filter towards lower frequencies (measurements shown on Fig. 16) at 9.6 GHz (FWHM $=0.4 \mathrm{GHz})$.

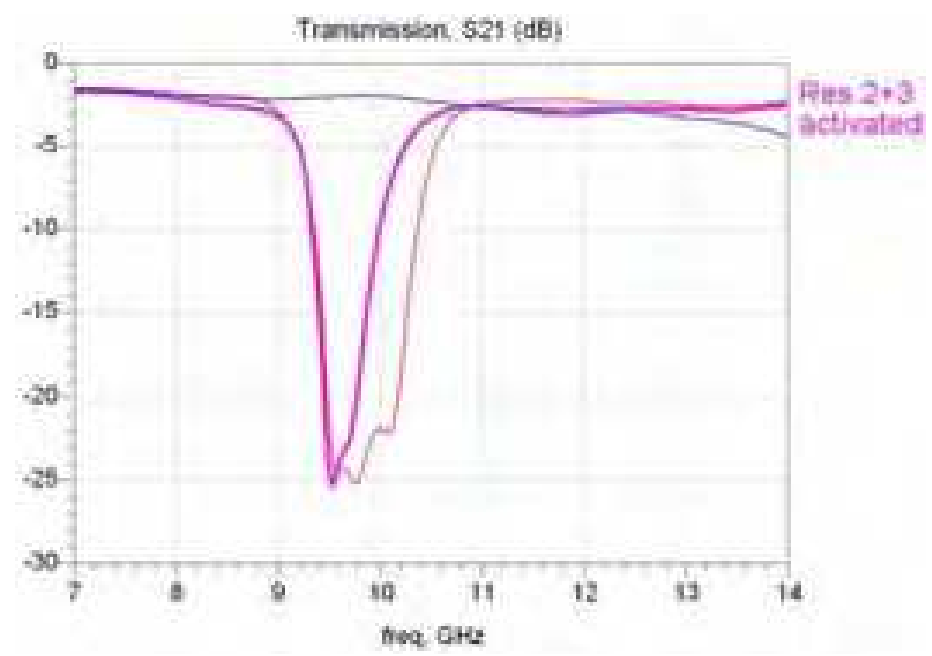

Fig. 16. S21 transmission measurement of the four-pole band stop filter when resonators 2 and 3 (as indicated on the Fig. 11) are simultaneously activated (curve in magenta, compared with the response of the non-activated filter, the red curve and the response of the totally activated filter, blue curve).

We presented above the concept of an $\mathrm{VO}_{2}$ - based electrical switch which can be discretely activated using a Ni:ta-C micro-heating element. These resistivity-switching functions were introduced in a more complex design for fabrication of a band-stop filter with tunable absorption bands and bandwidth operating in the $9-11 \mathrm{GHz}$ frequency domain. Although the device can be further optimized in for obtaining better performancesz we wanted to demonstrate that $\mathrm{VO}_{2}$ material-based components are serious candidates for RF-microwave switching and microwave reconfigurable devices.

\section{Conclusion}

The $\mathrm{VO}_{2}$ material fabricated using the PLD technique results in crystalline thin films performing sharp, high amplitude SMT phase transition and with very good electrical properties. The electrical and temperature-activated $\mathrm{VO}_{2}$-based switches are promising devices for fabrication of tunable filters and other complex functions in the RF/ microwave domains. The results presented so far are of the state-of-the-art international level concerning the elaboration and characterization of thin films $\mathrm{VO}_{2}$ of and their integration in practical microwave (and optical) devices. Further applications we are currently developing concerns complex broadband devices employed in the telecommunication networks in the millimeter-wave domain (3-terminal type fast switches, phase shifters, broadband power limiting devices based on microwave power induced SMT in vanadium dioxide, tunable bandpass filter that combines split ring resonators (SRRs) and vanadium dioxide $\left(\mathrm{VO}_{2}\right)$ - 
based microwave switches etc.) as well as the design of optical devices for applications using miniature laser systems or optoelectronics (optical switches, optical filters, variables attenuators and modulators etc.). The realization of these new type of devices widens a new and extremely rich activity in the field of device fabrication for millimeter-wave reconfigurable systems or for integrated optics and optical communication systems.

\section{References}

Ben-Messaoud, T.; Landry, G.; Gariépy, J.P.; Ramamoorthy, B.; Ashrit, P.V. \& Haché, A. (2008). High contrast optical switching in vanadium dioxide thin films. Opt. Commun. 281 (24), pp. 6024-6027

Cavalleri, A.; Tóth, Cs.; Siders, C.W.; Squier, J.A.; Ráksi, F.; Forget P. \& Kieffer, J. C. (2001). Femtosecond Structural Dynamics in VO2 during an Ultrafast Solid-Solid Phase Transition. Physical Review Letters, 87(23) 237401-1 - 237401-4

Cavalleri, A.; Dekorsky, Th.; Chong, H.H.W.; Kieffer, J.C. \& Schoenlein, R.W. (2004). Evidence for a structurally-driven insulator-to-metal transition in VO2: A view from the ultrafast timescale. Phys. Rev. B. rapid Commun. 70, 161102(R)

Cavalleri, A.; Rini, M.; Chong, H.H.W.; Fourmaux, S.; Glover, T.E.; Heimann, P.A.; Kieffer, J.C. \& Schoenlein, R.W. (2005). Band-selective measurement of Electronic Dynamics in VO2 using Femtosecond Near Edge X-ray Absorption. Phys. Rev. Lett. 95, 067405,

Chen, C.; Wang, R.; Shang, L. \& Guo, C. (2008). Gate-field-induced phase transitions in VO2: Monoclinic metal phase separation and switchable infrared reflections. Appl. Phys. Lett. 93, art. No.171101

Chrisey, D.B. \& Hubler, G.K. (1994). Pulsed Laser Deposition of Thin Films, Wiley/ Interscience New York, 1994, ISBN 0-471-59218-8

Crunteanu, A.; Dumas-Bouchiat, F.; Champeaux, C.; Catherinot, A.; Pothier, A. \& P. Blondy. (2007). Microwave Switching Functions Using Reversible Metal-Insulator Transition (MIT) in VO2 Thin Films. 37th European Microwave Conference (EuMC), paper EuMC01-4, 8-12 October 2007, Munich, Germany

Dumas-Bouchiat, F.; Nagaraja, H. S.; Rossignol, F.; Champeaux, C.; Trolliard, G.; Catherinot, A. \& Givord, D. (2006). Cobalt cluster-assembled thin films deposited by low energy cluster beam deposition: Structural and magnetic investigations of deposited layers. J. Appl. Phys. 100 (6), 064304

Dumas-Bouchiat, F.; Champeaux, C.; Catherinot, A.; Crunteanu, A. \& Blondy, P. (2007). RFMicrowave switches based on reversible semiconductor-metal transition of V02 thin films synthetized by pulsed laser deposition. Applied Physics Letters, 91, pp.223505-1-3

Dumas-Bouchiat, F.; Champeaux, C.; Catherinot, A.; Givernaud, J.; Crunteanu, A. \& P. Blondy (2009). RF Microwave Switches Based On Reversible Metal-Semiconductor Transition Properties Of VO2 Thin Films: An Attractive Way To Realise Simple RF Microelectronic Devices. Materials and Devices for Smart Systems III, edited by J. Su, L-P. Wang, Y. Furuya, S. Trolier-McKinstry, J. Leng, MRS Symp. Proc. Vol. 1129, Warrendale, PA, 2009, paper 1129-V14-01

Dragoman, M.; Cismaru, A.; Hartnagel, H. \& Plana, R. (2006). Reversible metalsemiconductor transitions for microwave switching applications. Appl. Phys. Lett. 88, 073503-1 - 073503-3 
Eason, R. (2007). Pulsed laser deposition of thin films: applications-led growth of functional materials, Wiley/ Interscience, ISBN 978-0-471-44709-2

Fan, J.C.C.; Feterman, H.R.; Bachner, F.J.; Zavracky, P.M. \& Parker, C.D. (1977). Thin-film $\mathrm{VO}_{2}$ submillimiter-wave modulators and polarizers. Appl. Phys. Lett. 31 (1), 11-13

Garry, G.; Durand, O. \& Lordereau, A. (2004). Structural, electrical and optical properties of pulsed laser deposited $\mathrm{VO}_{2}$ thin films on $\mathrm{R}$ - and C-sapphire planes. Thin Solid Films 453,427

Gevorgian, S. (2008). Tuneable Materials for Agile Microwave devices, an overview. 38 th European Microwave Conference Workshop WWE-6 (EuMC/EuMIC/EuWiT) "Reconfigurable RF Systems", paper WWE-6-6, 27-31 October 2008, Amsterdam, The Netherlands

Givernaud J.; Champeaux, C.; Catherinot, A.; Pothier, A.; Blondy, P. \& Crunteanu A. (2008). Tunable band stop filters based on metal insulator transition in vanadium dioxide thin films. IEEE MTT-S International Microwave Symposium Digest, IMS 2008, paper WEP1D-02, 15-20 June 2008, Atlanta, GA, USA

Givernaud, J.; Crunteanu, A.; Pothier, A.; Champeaux, C.; Catherinot, A. \& Blondy, P. (2009). CPW Self-resetting Power Limiting Devices Based on Microwave Power Induced Semiconductor-Metal Transition in Vanadium Dioxide. IEEE MTT-S International Microwave Symposium, IMS 2009, paper TU2E-5, 7-12 June 2009, Boston, MA, USA.

Griffiths, C. H. \& Eastwood, H. K. (1974). Influence of stoichiometry on the metalsemiconductor transition in vanadium dioxide. J. Appl.Phys. 45, 2201-2206

Guzman, G.; Beteille, F.; Morineau R. \& Livage, J. (1996). Electrical switching in VO2 sol-gel films. J. Mater. Chem. 6(3), 505-506

Hood, P. J. \& DeNatale, J. F. (1991). Millimeter-wave dielectric properties of epitaxial vanadium dioxide thin films. Appl. Phys. Lett., Vol. 70, No. 1, pp. 376-381

Jiang L. \& Carr, W.N. (2004). Design, fabrication and testing of a micromachined thermooptical light modulator based on a vanadium dioxide array. J. Micromech. Microeng. $14833-840$

Kim, C.; Shin J.S. \& Ozaki, H. (2007). Effect of W doping in metal-insulator transition material $\mathrm{VO}_{2}$ by tunnelling spectroscopy. J. Phys. Condens. Matter 19, 096007-1-7

Kim, H.-T.; Chae, B.-G.; Youn, D.-H.; Maeng, S.-L.; Kim, G.; Kang, K.-Y. \& Lim, Y.-S. (2004). Mechanism and observation of Mott transition in VO2-based two- and threeterminal devices. New J. Phys. 6, 52-70

Kim, H.-T.; Kim, B.-J.; Lee, Y. W.; Chae, B.-G. \& Yun, S.J. (2008). Switching of the Mott transition based on hole-driven MIT theory. Physica B 403, 1434-1436

Kitahiro I. \& Watanabe, A. (1967). Shift of transition temperature of vanadium dioxide crystals. Jpn. J. Appl. Phys. 6, 1023-1024

Laad, M. S.; Craco, L. \& Muller-Hartmann, E. (2006). Metal-insulator transition in rutilebased $\mathrm{VO}_{2}$. Phys. Rev. B 73, 195120

Lacroix, B.; Pothier, A.; Crunteanu, A.; Cibert, C.; Dumas-Bouchiat, F.; Champeaux, C.; Catherinot, A. \& Blondy, P. (2007). Sub-microsecond RF MEMS switched capacitors. IEEE Trans. Microwave Theory Tech. 55, 1314

Lee, Y.W.; Kim, B.J.; Choi, S.; Kim, H.-T.; \& Kim, G. (2007). Photo-assited electrical gating in a two-terminal device based on vanadium dioxide film. Optics Express 15 (19), 12108-12113 
Li, G.; Wang, X.; Liang, J.; Ji, A.; Hu, M.; Yang, F.; Liu, J.; Wu, N. \& Chen, H. (2008). Low Temperature Deposited Nano-structured Vanadium Oxide Thin Films for Uncooled Infrared Detectors. $2^{\text {nd }}$ IEEE International Nanoelectronics Conference (INEC 2008), pp. 921- 923, March 24-27, 2008, Pudong- Shanghai, China

Manning, T.D.; Parkin, I.P.; Clark, R.J.H.; Sheel, D.; Pemble, M.E. \& Vernadou, D. (2002). Intelligent window coatings: atmospheric pressure chemical vapour deposition of vanadium oxides. J. Mater. Chem. 12, 2936-2939

Morin, F. (1959). Oxide which shows a metal-to-insulator transition at the high temperature. Phys. Rev. Lett. 3, 34

Mott, N.F. (1968). Metal-Insulator Transition. Review of Modern Physics 40(4), pp. 677-683

Orlianges, J.C.; Champeaux, C.; Catherinot, A.; Pothier, A.; Blondy, P.; Abelard, P. \& Angleraud, B. (2004). Electrical properties of pure and metal-doped pulsed laser deposited carbon films. Thin Solid Films 453-454, pp. 291-295

Orlianges, J.C.; Pothier, A.; Mercier, D.; Blondy, P.; Champeaux, C.; Catherinot, A.; De Barros, M.I. \& Pavant, S. (2005). Application of aluminum oxide and ta-C thin films deposited at room temperature by PLD in RF-MEMS fabrication. Thin Solid Films 482 (1-2), pp. 237-241

Pergament, A. (2003). Metal-insulator transition: the Mott criterion and coherence length. J. Phys.: Condens. Matter 15, 3217-3223

Pozar, D. M. (2005). Microwave Engineering - 3rd ed., J. Wiley \& Sons

Qazilbash, M. M.; Brehm, M.; Chae, B.-G.; Ho, P.-C.; Andreev, G. O.; Kim, B.-J.; Yun, S.J.; Balatsky, A.V.; Maple, M. B.; Keilmann, F.; Kim, H.-T. \& Basov, D. N. (2007). Mott transition in $\mathrm{VO}_{2}$ revealed by infrared spectroscopy and nano-imaging. Science 318, 1750

Qazilbash, M.M.; Li, Z.Q.; Podzorov, V.; Brehm, M.; Keilmann, F.; Chae, B.G.; Kim, H.T. \& Basov, D.N. (2008). Electrostatic modification of infrared response in gated structures based on VO2. Appl. Phys. Lett. 92 (24), art. no. 241906

Rebeiz, G. M. (2003). RF MEMS Theory, Design, and Technology, New Jersey: J. Wiley \& Sons

Richardson, M.A. \& Coath, J.A. (1998). Infrared optical modulators for missile testing. Optics \& Laser Technology 30, 137-140

Sakai, J. \& Kurisu, M. (2008). Effect of pressure on the electric-field-induced resistance switching of VO2 planar-type junctions. Phys. Rev. B 78(3), art. No. 033106

Stefanovich, G.; Pergament A. \& Stefanovich, D. (2000). Electrical switching and Mott transition in $\mathrm{VO}_{2}$. J. Phys.: Condens. Matter, Vol. 12, pp. 8837-8845

Stotz, M.; Fritze, S.-D.; Downar, H. \& Wenger, J. (1999). Thermally Controlled Coplanar Microwave Switches. 29th European Microwave Conference Proceedings, pp.415-418, 57 October 1999 Munich, Germany

Verleur, H.W.; Barker Jr., A. S. \& Berglund, C.N. (1968). Optical properties of $\mathrm{VO}_{2}$ between 0.25 and 5 eV. Phys. Rev. 172 (3), 788-798

Wang, W.; Luo, Y.; Zhang, D. \& Luo, F. (2006). Dynamic optical limiting experiments on vanadium dioxide and vanadium pentoxide thin films irradiated by a laser beam. Applied Optics Vol. 45, No. 14, pp.3378-3381

Yi, X.; Chen, S.; Wang, Y.; Xiong, B. \& Wang, H. (2002). VO2-based infrared microbolometer array. Intl. J. of Infrared and Millimeter Waves 23(12), 1699- 1704 
Youn, D.; Lee, J.; Chae, B.; Kim, H.; Maeng, S. \& Kang, K. (2004). Growth optimization and electrical characteristics of $\mathrm{VO}_{2}$ films on amorphous $\mathrm{SiO}_{2} / \mathrm{Si}$ substrates. J. Appl. Phys. 95, 1407

Zylbersztejn, A. \& Mott, N.F. (1975). Metal-insulator transition in vanadium dioxide. Phys. Rev. B 11(11), 4383-4395 


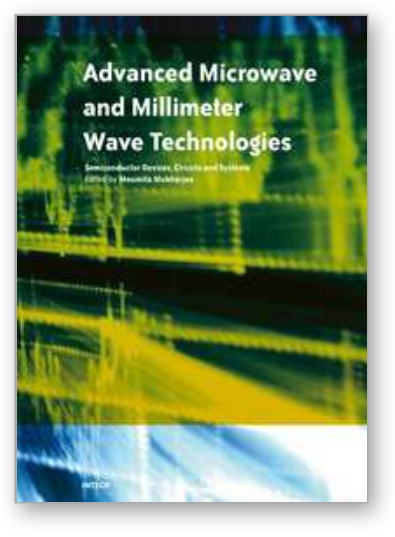

\section{Advanced Microwave and Millimeter Wave Technologies Semiconductor Devices Circuits and Systems}

Edited by Moumita Mukherjee

ISBN 978-953-307-031-5

Hard cover, 642 pages

Publisher InTech

Published online 01, March, 2010

Published in print edition March, 2010

This book is planned to publish with an objective to provide a state-of-the-art reference book in the areas of advanced microwave, MM-Wave and $\mathrm{THz}$ devices, antennas and systemtechnologies for microwave communication engineers, Scientists and post-graduate students of electrical and electronics engineering, applied physicists. This reference book is a collection of 30 Chapters characterized in 3 parts: Advanced Microwave and MM-wave devices, integrated microwave and MM-wave circuits and Antennas and advanced microwave computer techniques, focusing on simulation, theories and applications. This book provides a comprehensive overview of the components and devices used in microwave and MM-Wave circuits, including microwave transmission lines, resonators, filters, ferrite devices, solid state devices, transistor oscillators and amplifiers, directional couplers, microstripeline components, microwave detectors, mixers, converters and harmonic generators, and microwave solid-state switches, phase shifters and attenuators. Several applications area also discusses here, like consumer, industrial, biomedical, and chemical applications of microwave technology. It also covers microwave instrumentation and measurement, thermodynamics, and applications in navigation and radio communication.

\section{How to reference}

In order to correctly reference this scholarly work, feel free to copy and paste the following:

Crunteanu Aurelian, Givernaud Julien, Blondy Pierre, Orlianges Jean-Christophe, Champeaux Corinne and Catherinot Alain (2010). Exploiting the Semiconductor-Metal Phase Transition of VO2 Materials: a Novel Direction towards Tuneable Devices and Systems for RF-Microwave Applications, Advanced Microwave and Millimeter Wave Technologies Semiconductor Devices Circuits and Systems, Moumita Mukherjee (Ed.), ISBN: 978-953-307-031-5, InTech, Available from: http://www.intechopen.com/books/advanced-microwave-andmillimeter-wave-technologies-semiconductor-devices-circuits-and-systems/exploiting-the-semiconductormetal-phase-transition-of-vo2-materials-a-novel-direction-towards-tunea

\section{INTECH}

open science | open minds

\section{InTech Europe}

University Campus STeP Ri

Slavka Krautzeka 83/A

51000 Rijeka, Croatia

Phone: +385 (51) 770447

\section{InTech China}

Unit 405, Office Block, Hotel Equatorial Shanghai

No.65, Yan An Road (West), Shanghai, 200040, China

中国上海市延安西路65号上海国际贵都大饭店办公楼 405 单元

Phone: +86-21-62489820 
Fax: +385 (51) 686166

Fax: +86-21-62489821

www.intechopen.com 
(C) 2010 The Author(s). Licensee IntechOpen. This chapter is distributed under the terms of the Creative Commons Attribution-NonCommercialShareAlike-3.0 License, which permits use, distribution and reproduction for non-commercial purposes, provided the original is properly cited and derivative works building on this content are distributed under the same license. 